\title{
Behavioral Modeling of Chokes for EMI Simulations in Power Electronics
}

\author{
Ivica Stevanović, Senior Member, IEEE, Stanislav Skibin, Member, IEEE, Mika Masti, and Matti Laitinen
}

\begin{abstract}
In this paper, a novel generalized behavioral model and the corresponding parameter extraction procedure for singleand three-phase chokes are presented. The model takes into account common-mode and differential-mode behavior of the choke and can be applied to modeling all types of chokes used in electromagnetic interference filters for power electronics devices. Depending on the level of the model complexity, the model parameters can be obtained either from a straightforward equation-based or an optimization-based parameter extraction procedure. The accuracy of the model and the validity of the method are demonstrated on several examples of single- and three-phase chokes with ferrite and nanocrystalline cores.
\end{abstract}

Index Terms-Common mode (CM), common-mode choke, dccoupled choke, differential mode (DM), electromagnetic interference (EMI) simulations, equivalent circuit, SPICE models.

\section{INTRODUCTION}

I N POWER electronic converters and motor drives, most of the power filters are based on passive elements, where inductors play a major role in increasing series impedance for both common-mode (CM) and differential-mode (DM) currents [1][5]. However, the inductors' frequency characteristics may be much different from ideal design when operating at high frequencies, mostly due to nonlinear characteristics of ferrite core, leakage inductance, and parasitic capacitance of windings [6]. This may greatly affect the electromagnetic interference (EMI) levels of the whole circuit. Therefore, it is of paramount interest to have appropriate high-frequency models for the inductors when selecting them in the design of the power filters and ensuring that the EMI limits have been achieved.

The inductor models can be generally categorized into two large classes: physical and behavioral. The first category refers to numerical models where a system of physical equations is constructed and solved using the geometry and material information of a choke [7]-[18]. Physical methods need full geometry and electrical parameter description of windings and ferrite core, and are time consuming [6]. While physical modeling techniques can be effectively used in the choke design, behavioral models are more suitable for system-level simulations.

Manuscript received March 22, 2012; revised May 9, 2012; accepted May 29, 2011. Date of current version September 27, 2012. Recommended for publication by Associate Editor P. Tenti.

I. Stevanović and S. Skibin are with ABB Corporate Research, CH-5405 Baden-Dättwil, Switzerland (e-mail: ivica.stevanovic@ch.abb.com; stanislav. skibin@ch.abb.com).

M. Masti and M. Laitinen are with ABB Oy Drives, 00381 Helsinki, Finland (e-mail: mika.masti@fi.abb.com; matti.laitinen@fi.abb.com).

Color versions of one or more of the figures in this paper are available online at http://ieeexplore.ieee.org.

Digital Object Identifier 10.1109/TPEL.2012.2203319
Behavioral models are based on impedance or current/voltage measurements of a choke at different connection schemes. The measurement curves are fitted to a corresponding equivalent circuit or system of equations, which can be used in a circuit simulator [6], [19]-[22].

A high-frequency behavioral model of a single-phase CM inductor for EMI analysis has been presented in [6]. However, this model does not capture the DM behavior present in any CM choke operation. Methods for characterizing both CM and DM behavior of CM chokes are introduced in [19] and later in [21], where measured $s$-parameters are used as a target in an optimization procedure to obtain a set of equivalent circuit parameters, or in [22], where a set of impedance measurements and analytical formulas are used to extract the parameters of the high-frequency model of the coupled inductors. These methods are applicable to single-phase chokes only and do not seem to cover multiple resonances that appear in the measured CM and DM impedances. In our previous work [23]-[25], we have presented behavioral choke modeling technique equally applicable for both single- and three-phase chokes covering both CM and DM choke behavior and capturing multiple inner resonances that may appear in the choke impedance curves. This paper is a generalization of the previously reported modeling techniques with the following features:.

1) one SPICE compatible model for time domain and frequency domain simulations;

2) one model, covering CM and DM choke behavior;

3) one procedure for all types of chokes, used in EMI filters for power electronic devices (single phase, three phase, CM chokes, dc chokes, etc.);

4) equation- and/or optimization-based fitting technique.

The technique has been applied to several different chokes with both ferrite and nanocrystalline cores, and accurate models have been obtained in a large frequency range $100 \mathrm{~Hz}-$ $100 \mathrm{MHz}$, covering the conducted emission frequency band.

\section{MODEL TOPOLOGY}

\section{A. Single-Phase Choke}

Fig. 1 shows an equivalent model of a single-phase choke. This model is a general representation encompassing different models we have presented in our previous work [23]-[25]. The model has multiple CM and DM resonant stages in order to capture higher order resonances that may appear in the measured choke impedances. Each resonant stage consists of a pair of coupled inductors where the CM pairs have coupling coefficient $k_{\mathrm{C}}=1$, and the DM pairs $k_{\mathrm{D}}=-1$. These values ensure that ideally there is no DM coupling in the presence of $\mathrm{CM}$ 


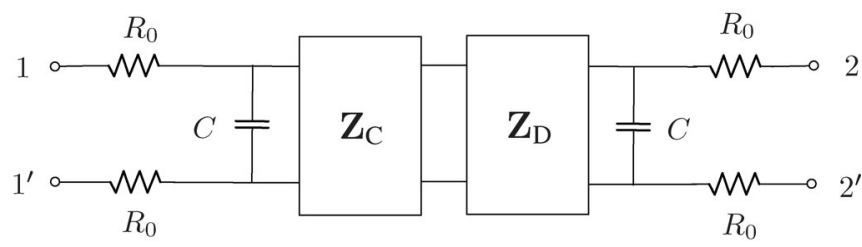

(a)

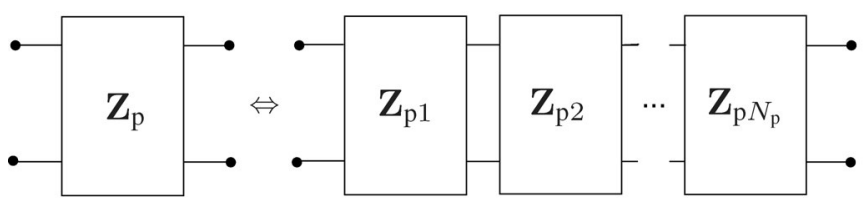

(b)
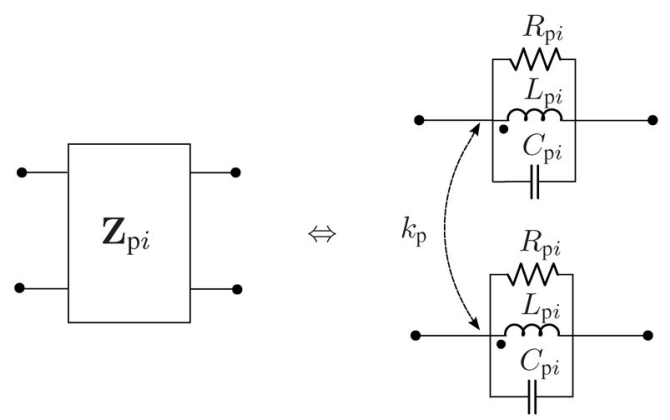

(c)

Fig. 1. Equivalent circuit for a single-phase choke. $i=1,2, \ldots, N_{\mathrm{p}}, \mathrm{p}=$ $\mathrm{C}, \mathrm{D}$, and $k_{\mathrm{C}}=1, k_{\mathrm{D}}=-1$.

currents only, and vice versa (see Figs. 2 and 3). $R_{\mathrm{p} i}$ stand for core resistances, reflecting the energy loss of the ferrite core due to hysteresis and eddy currents, and $C_{\mathrm{p} i}$ represent the distributed parasitic capacitances in the windings (intrawinding capacitances) for $\mathrm{CM}(\mathrm{p}=\mathrm{C})$ and $\mathrm{DM}(\mathrm{p}=\mathrm{D})$ emissions; $C$ is the parasitic capacitance between the windings (inter-winding capacitance) and $R_{0}$ is the parasitic resistance of the conductor windings. We suppose the windings to be of the same electrical parameters and perfectly symmetric.

We are interested in the impedances as seen from the generator when the choke is connected in the CM, DM, and open-circuit (OC) schemes (see Fig. 4). Taking into account the symmetry and the coupling effects between the inductors (see Figs. 2 and 3), it can be shown that the impedances in these three configurations can be written using the expressions given in (1)-(3) shown at the bottom of the next page.

\section{B. Three-Phase Choke}

A choke with three windings that are equally and symmetrically spaced will have an equivalent circuit similar to that one of the single-phase choke (see Fig. 5). Each resonant stage now consists of three coupled inductors where the CM triplets have coupling coefficients $k_{\mathrm{C}}=1$, and the DM triplets $k_{\mathrm{D}}=-0.5$. These values ensure that ideally there is no DM coupling in the presence of CM currents only, and vice versa (see Figs. 6 and 7). The remaining circuit parameters have the same meaning as in the case of the single-phase choke.

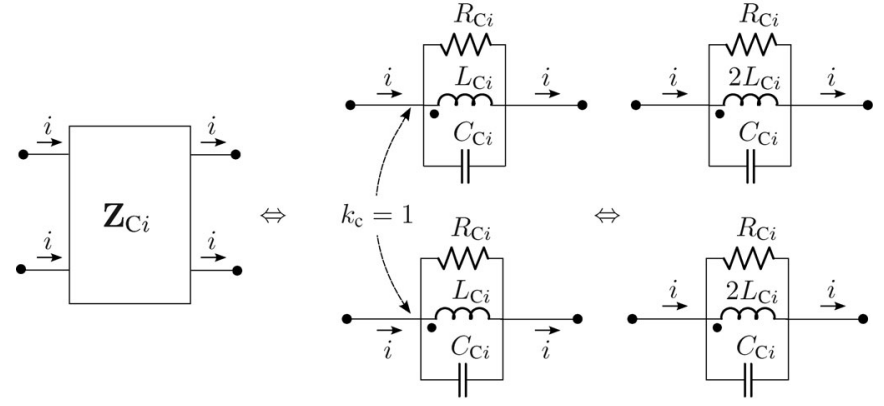

(a)

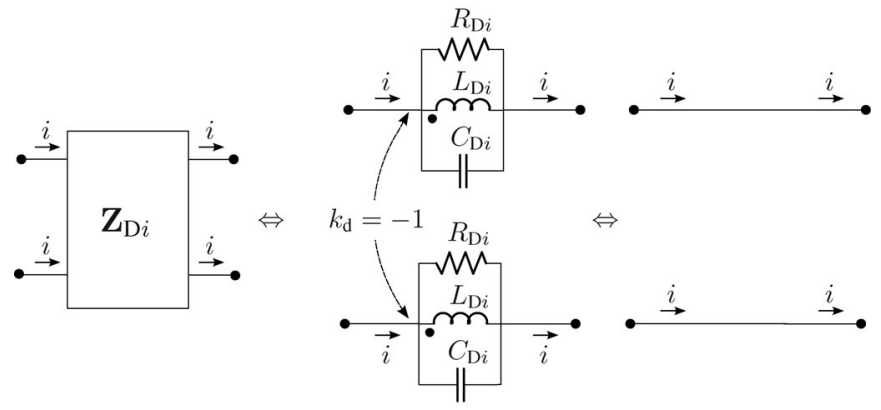

(b)

Fig. 2. Equivalent circuit for a single-phase impedance block with $\mathrm{CM}$ currents: (a) CM choke block and (b) DM choke block.

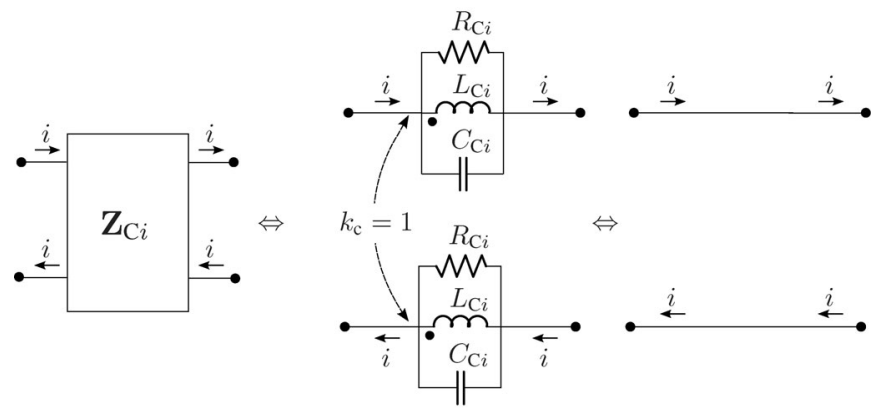

(a)

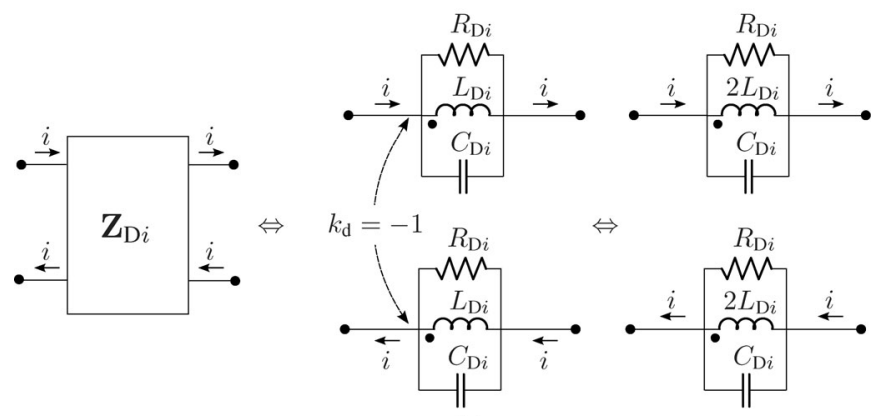

(b)

Fig. 3. Equivalent circuit for a single-phase impedance block with DM currents: (a) CM choke block and (b) DM choke block.

The impedances as seen from the generator when the choke is connected in the CM, DM, and OC schemes (see Fig. 8) 


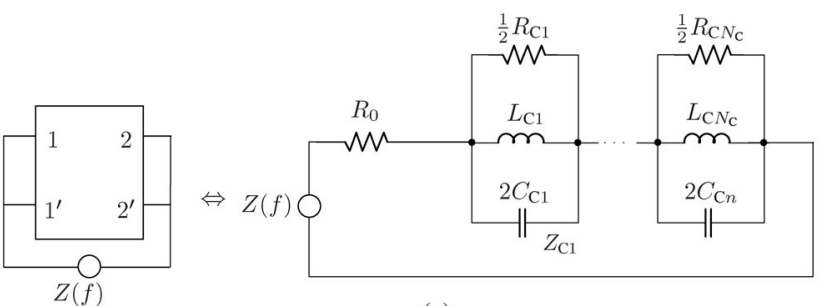

(a)

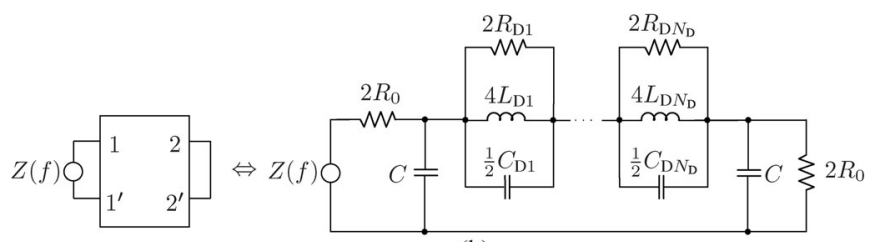

(b)

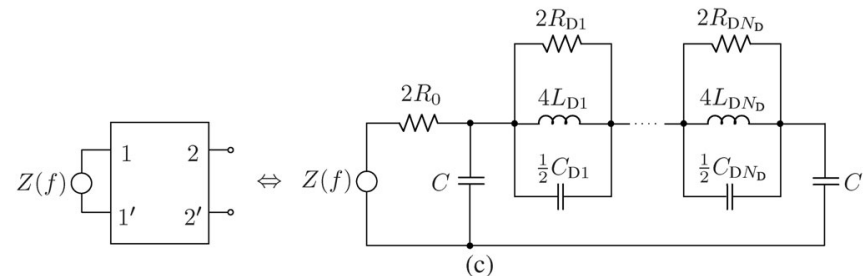

Fig. 4. Equivalent circuits corresponding to the measurement setups for parameter extraction of the single-phase choke. (a) CM. (b) DM. (c) OC.

can be written using the expressions given in (4)-(6) shown at the bottom of the page. As can be seen, they correspond to the expressions for the single-phase choke [see (1)-(3), shown at the bottom of the page], so that the parameter extraction procedure used for the single-phase choke can be directly applied for the

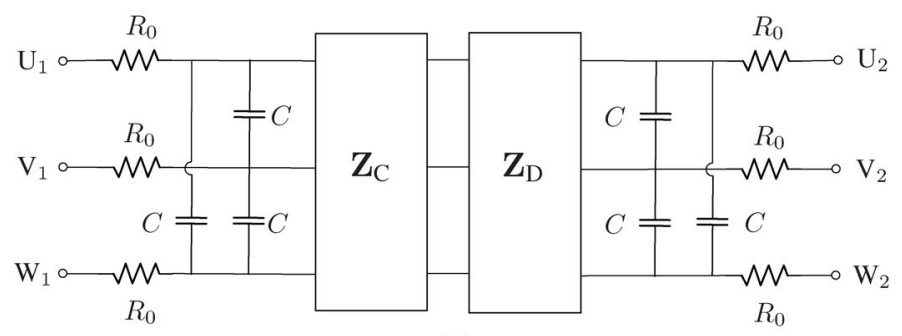

(a)

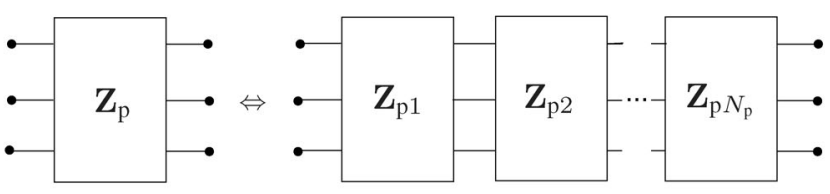

(b)
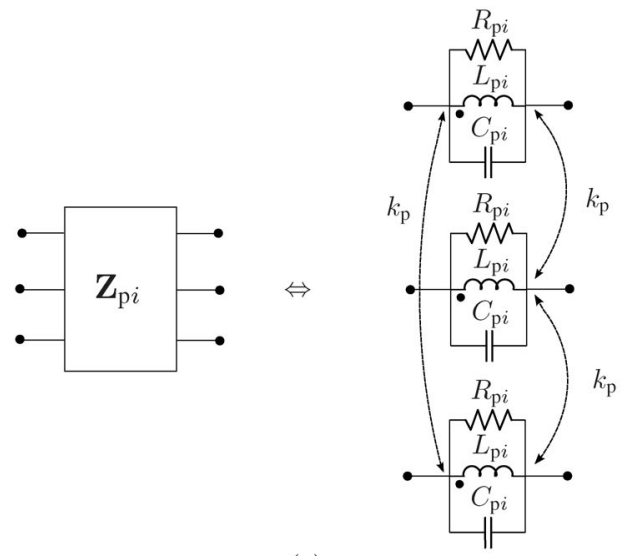

(c)

Fig. 5. Equivalent circuit for a three-phase choke. $i=1,2, \ldots, N_{\mathrm{p}}, \mathrm{p}=$ $\mathrm{C}, \mathrm{D}$, and $k_{\mathrm{C}}=1, k_{\mathrm{D}}=-0.5$.

$$
\begin{aligned}
& Z_{\mathrm{CM}}=R_{0}+\sum_{i=1}^{N_{\mathrm{C}}} \frac{\mathrm{j} \omega R_{\mathrm{C} i} L_{\mathrm{C} i}}{R_{\mathrm{C} i}-2 \omega^{2} R_{\mathrm{C} i} L_{\mathrm{C} i} C_{\mathrm{C} i}+2 \mathrm{j} \omega L_{\mathrm{C} i}} \\
& Z_{\mathrm{DM}}=2 R_{0}+\left(\mathrm{j} \omega C+\left(\sum_{i=1}^{N_{\mathrm{D}}} \frac{4 \mathrm{j} \omega R_{\mathrm{D} i} L_{\mathrm{D} i}}{R_{\mathrm{D} i}-2 \omega^{2} R_{\mathrm{D} i} L_{\mathrm{D} i} C_{\mathrm{D} i}+2 \mathrm{j} \omega L_{\mathrm{D} i}}+\frac{2 R_{0}}{1+2 \mathrm{j} \omega R_{0} C}\right)^{-1}\right)^{-1}
\end{aligned}
$$

and

$$
\begin{aligned}
& Z_{\mathrm{OC}}=2 R_{0}+\left(\mathrm{j} \omega C+\left(\sum_{i=1}^{N_{\mathrm{D}}} \frac{4 \mathrm{j} \omega R_{\mathrm{D} i} L_{\mathrm{D} i}}{R_{\mathrm{D} i}-2 \omega^{2} R_{\mathrm{D} i} L_{\mathrm{D} i} C_{\mathrm{D} i}+2 \mathrm{j} \omega L_{\mathrm{D} i}}+\frac{1}{\mathrm{j} \omega C}\right)^{-1}\right)^{-1} \\
& Z_{\mathrm{CM}}=\frac{2}{3} R_{0}+\sum_{i=1}^{N_{\mathrm{C}}} \frac{\mathrm{j} \omega R_{\mathrm{C} i} L_{\mathrm{C} i}}{R_{\mathrm{C} i}-3 \omega^{2} R_{\mathrm{C} i} L_{\mathrm{C} i} C_{\mathrm{C} i}+3 \mathrm{j} \omega L_{\mathrm{C} i}} \\
& Z_{\mathrm{DM}}=\frac{3}{2} R_{0}+\left(2 \mathrm{j} \omega C+\left(\frac{3}{2} \sum_{i=1}^{N_{\mathrm{D}}} \frac{3 \mathrm{j} \omega R_{\mathrm{D} i} L_{\mathrm{D} i}}{2 R_{\mathrm{D} i}-3 \omega^{2} R_{\mathrm{D} i} L_{\mathrm{D} i} C_{\mathrm{D} i}+3 \mathrm{j} \omega L_{\mathrm{D} i}}+\frac{\frac{3}{2} R_{0}}{1+3 \mathrm{j} \omega R_{0} C}\right)^{-1}\right)^{-1}
\end{aligned}
$$

and

$$
Z_{\mathrm{OC}}=\frac{3}{2} R_{0}+\left(2 \mathrm{j} \omega C+\left(\frac{3}{2} \sum_{i=1}^{N_{\mathrm{D}}} \frac{3 \mathrm{j} \omega R_{\mathrm{D} i} L_{\mathrm{D} i}}{2 R_{\mathrm{D} i}-3 \omega^{2} R_{\mathrm{D} i} L_{\mathrm{D} i} C_{\mathrm{D} i}+3 \mathrm{j} \omega L_{\mathrm{D} i}}+\frac{1}{2 \mathrm{j} \omega C}\right)^{-1}\right)^{-1}
$$




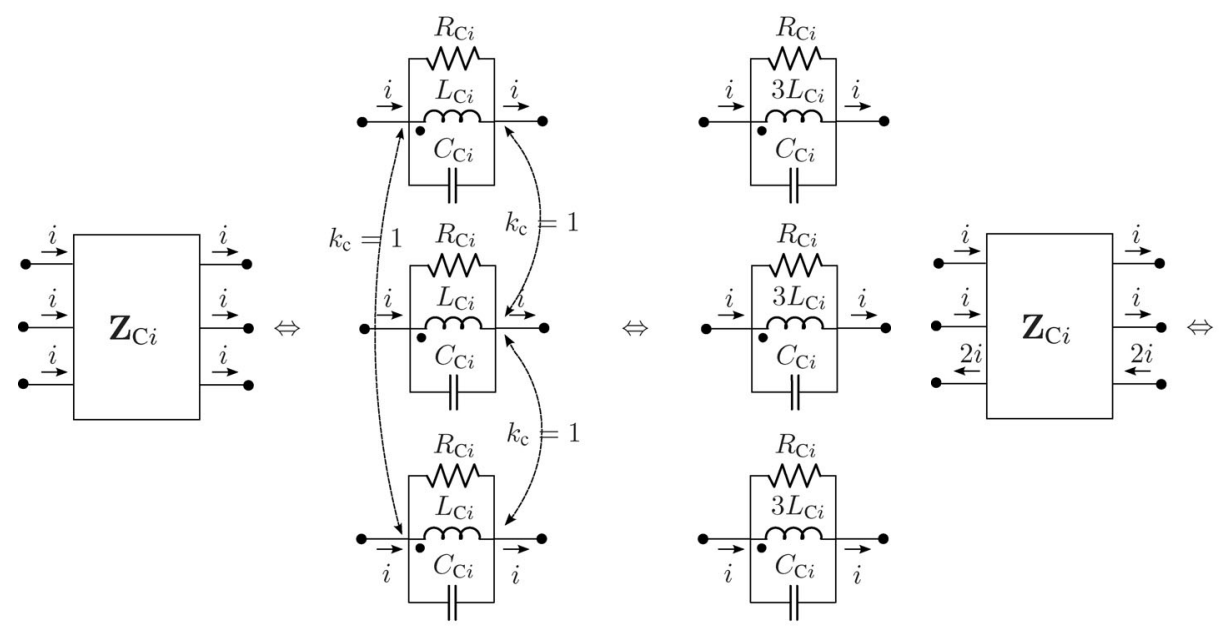

(a)

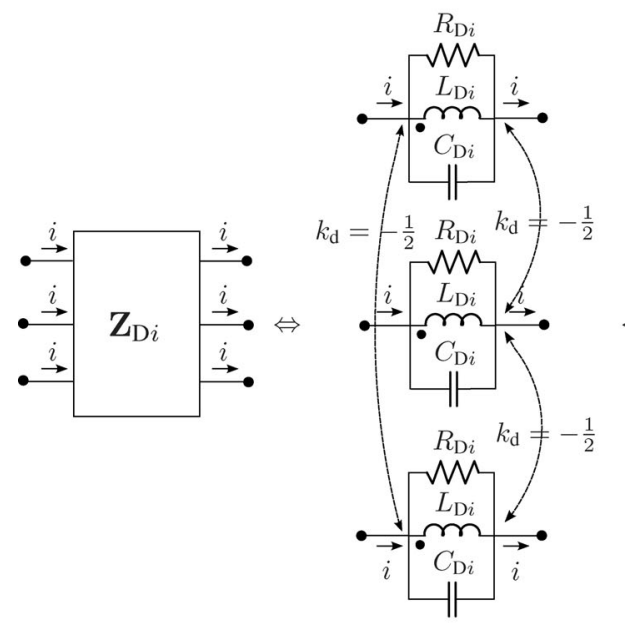

(b)
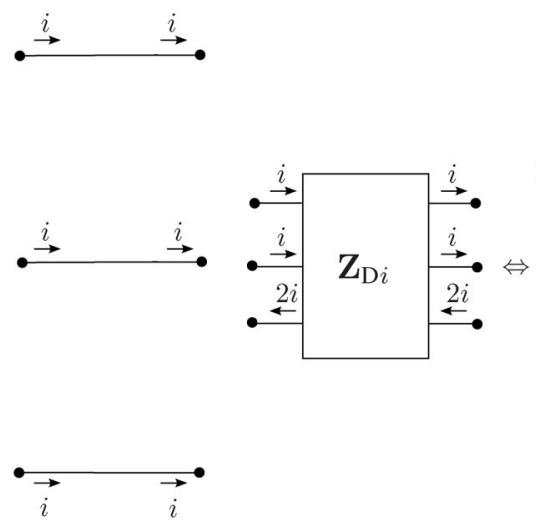

Fig. 6. Equivalent circuit for a three-phase resonant stage with $\mathrm{CM}$ currents: (a) CM stage and (b) DM stage.

three-phase choke as well. For brevity, we will present in detail only the parameter extraction of the single-phase choke; using analogy, the parameter extraction for three-phase chokes can be deduced directly and it will be presented here in terms of final formulas and expressions.

\section{PARAMETER EXTRACTION}

In order to extract the $R L C$ parameters of the model from the measurements, we analyze the following special cases:

1) Single Resonance: If only one resonance can be observed in the measured CM, DM, and OC impedances (dashed line in Fig. 9), the equivalent circuit can be represented with only one resonant stage for CM and DM blocks $\left(N_{\mathrm{C}}=N_{\mathrm{D}}=1\right)$. The parameter extraction procedure is straightforward and the parameters can be extracted from measurements using a couple of analytical formulas. This extraction procedure is outlined in Section III-A.

2) Multiple Resonances: If several impedance resonances can be observed in the frequency range of interest, in in two ways.

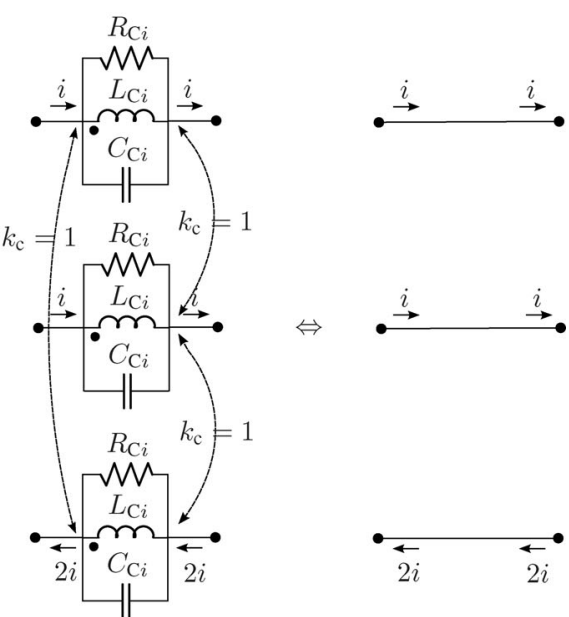

(a)
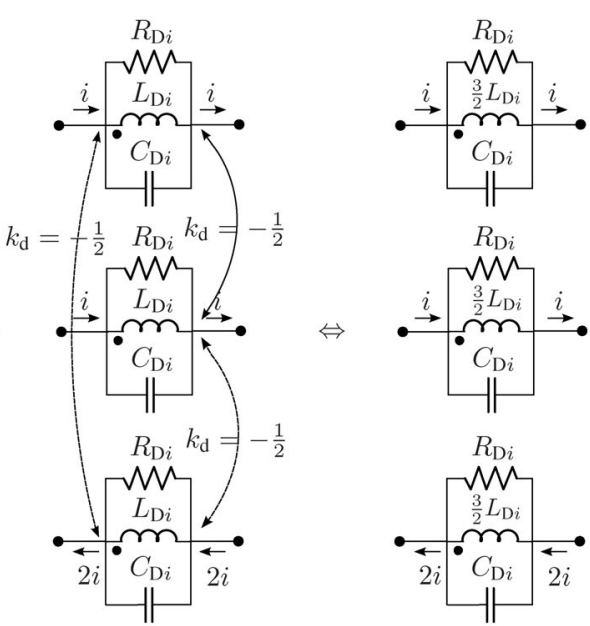

(b)

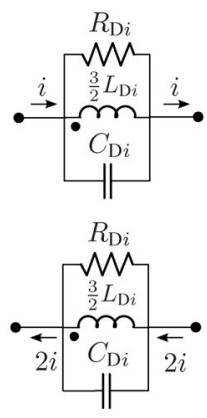

Fig. 7. Equivalent circuit for a three-phase resonant stage with DM currents: (a) CM stage and (b) DM stage.

order to include those resonances in the model, one needs to use as many resonant stages as there are resonances to be modeled $\left(N_{\mathrm{C}}, N_{\mathrm{D}} \geq 1\right)$. In this case, we can proceed

a) $C=0$ : If the interwinding capacitance is not of particular interest and can be neglected, it is possible to extract the parameters using measurements and a set of iterative analytical formulas without the need for optimization. This extraction procedure is detailed in Section III-B.

b) $C \neq 0$ : If the interwinding capacitance cannot be neglected, an application of the iterative, analytical equation-based algorithm for the calculation of the circuit elements from (1)-(3) is not possible. In this case, the whole parameter set can be extracted from measurements using different optimization techniques. In Section III-C, we present a genetic algorithm approach to the fitting of choke's impedance curves, resulting in the set of desired circuit parameters. 


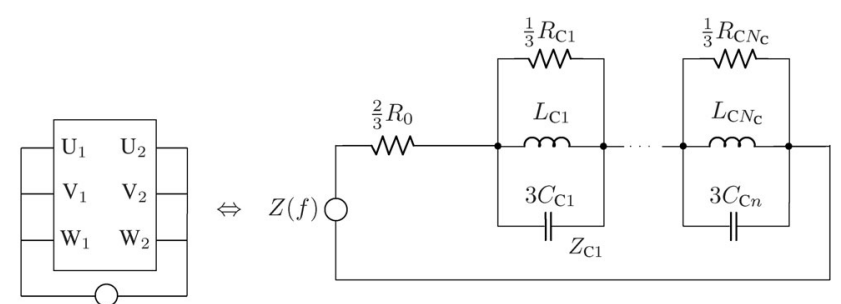

(a)

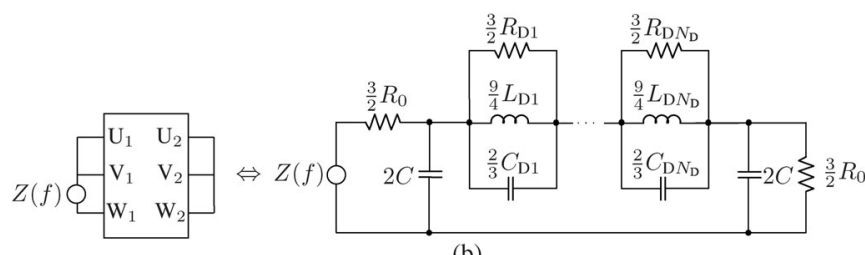

(b)

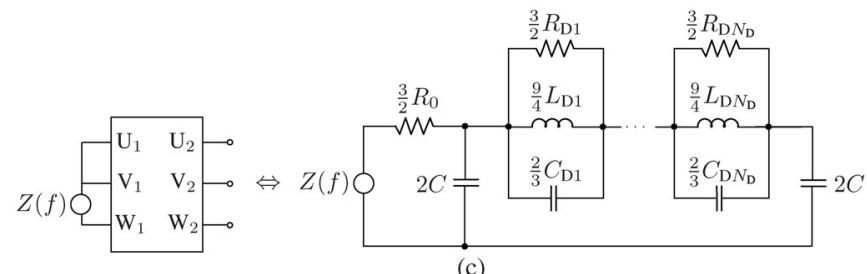

(c)

Fig. 8. Equivalent circuits corresponding to the measurement setups for parameter extraction of the three-phase choke. (a) CM. (b) DM. (c) OC.

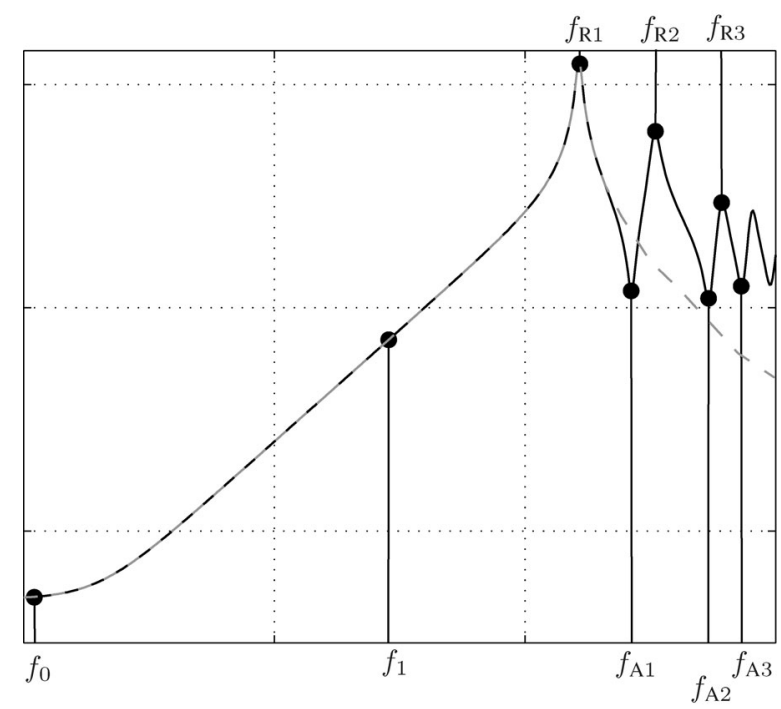

Fig. 9. Typical frequency behavior of the CM and DM choke impedances with single resonance (dashed line) and higher order resonances (solid line).

We will derive in detail the equations for the extraction of the parameters for the single-phase choke only. Taking into account the similarity in the equations for CM, DM, and OC impedances, the parameter extraction for the three-phase choke follows the same lines and only the final results will be presented here.

\section{A. Single-Resonance Case}

In case of $N_{\mathrm{C}}=N_{\mathrm{D}}=1$, the general formulas given in (1)(3) reduce to the following set of equations:

$$
\begin{aligned}
& Z_{\mathrm{CM}}=R_{0}+\frac{\mathrm{j} \omega R_{\mathrm{C}} L_{\mathrm{C}}}{R_{\mathrm{C}}-2 \omega^{2} R_{\mathrm{C}} L_{\mathrm{C}} C_{\mathrm{C}}+2 \mathrm{j} \omega L_{\mathrm{C}}} \\
& Z_{\mathrm{DM}}=2 R_{0}+\frac{4 \mathrm{j} \omega R_{\mathrm{D}} L_{\mathrm{D}}}{R_{\mathrm{D}}-2 \omega^{2} R_{\mathrm{D}} L_{\mathrm{D}}\left(C_{\mathrm{D}}+2 C\right)+2 \mathrm{j} \omega L_{\mathrm{D}}} \\
& Z_{\mathrm{OP}}=2 R_{0}+\frac{1}{\mathrm{j} \omega(2 C)} \frac{R_{\mathrm{D}}-2 \omega^{2} R_{\mathrm{D}} L_{\mathrm{D}}\left(C_{\mathrm{D}}+2 C\right)+2 \mathrm{j} \omega L_{\mathrm{D}}}{R_{\mathrm{D}}-2 \omega^{2} R_{\mathrm{D}} L_{\mathrm{D}}\left(C_{\mathrm{D}}+C\right)+2 \mathrm{j} \omega L_{\mathrm{D}}} .
\end{aligned}
$$

\section{Parameters Derived From the CM Impedance}

At dc $\left(f_{0}=0\right)$, the $\mathrm{CM}$ impedance is resistive and

$$
R_{0} \approx Z_{\mathrm{CM}}\left(f_{0}\right)
$$

At lower frequencies, the CM impedance is mostly inductive

$$
Z_{\mathrm{CM}}\left(f_{\mathrm{C} 1}\right) \approx \mathrm{j} \omega_{\mathrm{C} 1} L_{\mathrm{C}} \rightarrow L_{\mathrm{C}} \approx \frac{\left|Z_{\mathrm{CM}}\left(f_{\mathrm{C} 1}\right)\right|}{2 \pi f_{\mathrm{C} 1}} .
$$

The resonance in the $\mathrm{CM}$ impedance happens at

$$
f_{\mathrm{CR}}=\frac{1}{2 \pi \sqrt{2 L_{\mathrm{C}} C_{\mathrm{C}}}} \rightarrow C_{\mathrm{C}}=\frac{1}{8 \pi^{2} f_{\mathrm{CR}}^{2} L_{\mathrm{C}}} .
$$

At that frequency, the $\mathrm{CM}$ impedance is real and given by

$$
Z_{\mathrm{CM}}\left(f_{\mathrm{CR}}\right)=\frac{R_{\mathrm{C}}}{2} \rightarrow R_{\mathrm{C}}=2 Z_{\mathrm{CM}}\left(f_{\mathrm{CR}}\right) .
$$

\section{Parameters Derived From the DM Impedance}

At dc $\left(f_{0}=0\right)$, the DM impedance is resistive

$$
R_{0} \approx \frac{Z_{\mathrm{DM}}\left(f_{0}\right)}{4}
$$

At lower frequencies, the DM impedance is mostly inductive

$$
Z_{\mathrm{DM}}\left(f_{\mathrm{D} 1}\right) \approx 4 \mathrm{j} \omega_{\mathrm{D} 1} L_{\mathrm{D}} \rightarrow L_{\mathrm{D}} \approx \frac{\left|Z_{\mathrm{DM}}\left(f_{\mathrm{D} 1}\right)\right|}{8 \pi f_{\mathrm{D} 1}}
$$

The resonance in the DM impedance happens at

$$
f_{\mathrm{DR}}=\frac{1}{2 \pi \sqrt{2 L_{\mathrm{D}}\left(C_{\mathrm{D}}+2 C\right)}} \rightarrow C_{\mathrm{D}}+2 C=\frac{1}{8 \pi^{2} f_{\mathrm{DR}}^{2} L_{\mathrm{D}}} .
$$

At that frequency, the DM impedance is real and given by

$$
Z_{\mathrm{DM}}\left(f_{\mathrm{DR}}\right)=2 R_{\mathrm{D}} \rightarrow R_{\mathrm{D}}=\frac{Z_{\mathrm{DM}}\left(f_{\mathrm{DR}}\right)}{2} .
$$

\section{Parameters Derived From the OC Impedance}

At lower frequency, the impedance of the OC is mostly capacitive [see (9)]. Therefore, we have

$$
C=\frac{1}{4 \pi f_{\mathrm{O} 1}\left|Z_{\mathrm{OP}}\left(f_{\mathrm{O} 1}\right)\right|} \quad \text { and } \quad C_{\mathrm{D}}=\frac{1}{8 \pi^{2} f_{\mathrm{DR}}^{2} L_{\mathrm{D}}}-2 C .
$$

Tables I and II summarize the analytical formulas for parameter extraction of the single-phase and three-phase chokes, respectively, for the case of single resonance modeled. 
TABLE I

ANALYTICAL FORMULAS FOR PARAMETER EXTRACTION OF A Single-Phase Choke (Single Resonance)

\begin{tabular}{|c|c|}
\hline \multicolumn{2}{|c|}{ Single Phase, Single Resonance } \\
\hline $\mathrm{CM}$ & $\mathrm{DM}$ \\
\hline$R_{0} \approx \operatorname{Re}\left(Z_{\mathrm{CM}}\left(f_{\mathrm{C} 0}\right)\right)$ & or $R_{0} \approx \operatorname{Re}\left(Z_{\mathrm{DM}}\left(f_{\mathrm{D} 0}\right)\right) / 4$ \\
$L_{\mathrm{C}} \approx \frac{\left|Z_{\mathrm{CM}}\left(f_{\mathrm{C} 1}\right)\right|}{2 \pi f_{\mathrm{C} 1}}$ & $L_{\mathrm{D}} \approx \frac{\left|Z_{\mathrm{DM}}\left(f_{\mathrm{D} 1}\right)\right|}{8 \pi f_{\mathrm{D} 1}}$ \\
$C_{\mathrm{C}} \approx \frac{1}{8 \pi^{2} f_{\mathrm{CR} 1}^{2} L_{\mathrm{C}}}$ & $C_{\mathrm{D}}=\frac{1}{8 \pi^{2} f_{\mathrm{DR}}^{2} L_{\mathrm{D}}}-2 C$ \\
& $C=\frac{1}{4 \pi f_{\mathrm{O} 1}\left|Z_{\mathrm{OC}}\left(f_{\mathrm{O} 1}\right)\right|}$ \\
$R_{\mathrm{C}} \approx 2\left|Z_{\mathrm{CM}}\left(f_{\mathrm{CR} 1}\right)\right|$ & $R_{\mathrm{D}} \approx \frac{1}{2}\left|Z_{\mathrm{DM}}\left(f_{\mathrm{DR} 1}\right)\right|$ \\
\hline
\end{tabular}

TABLE II

ANALYTICAL FORMULAS FOR PARAMETER EXTRACTION of A Three-Phase Choke (Single Resonance)

\begin{tabular}{|c|c|}
\hline \multicolumn{2}{|c|}{ Three Phase, Single Resonance } \\
\hline$R_{0} \approx \frac{3}{2} \operatorname{Re}\left(Z_{\mathrm{CM}}\left(f_{\mathrm{C} 0}\right)\right)$ & or $R_{0} \approx \frac{1}{3} \operatorname{Re}\left(Z_{\mathrm{DM}}\left(f_{\mathrm{D} 0}\right)\right)$ \\
$L_{\mathrm{C}} \approx \frac{\left|Z_{\mathrm{CM}}\left(f_{\mathrm{C} 1}\right)\right|}{2 \pi f_{\mathrm{C} 1}}$ & $L_{\mathrm{D}} \approx \frac{2\left|Z_{\mathrm{DM}}\left(f_{\mathrm{D} 1}\right)\right|}{9 \pi f_{\mathrm{D} 1}}$ \\
$C_{\mathrm{C}} \approx \frac{1}{12 \pi^{2} f_{\mathrm{CR} 1}^{2} L_{\mathrm{C}}}$ & $C_{\mathrm{D}}=\frac{1}{6 \pi^{2} f_{\mathrm{DR} 1}^{2} L_{\mathrm{D}}}-3 C$ \\
& $C=\frac{1}{8 \pi f_{\mathrm{O} 1}\left|Z_{\mathrm{OC}}\left(f_{\mathrm{O} 1}\right)\right|}$ \\
$R_{\mathrm{C}} \approx 3\left|Z_{\mathrm{CM}}\left(f_{\mathrm{CR} 1}\right)\right|$ & $R_{\mathrm{D}} \approx \frac{2}{3}\left|Z_{\mathrm{DM}}\left(f_{\mathrm{DR} 1}\right)\right|$ \\
\hline
\end{tabular}

\section{B. Multiple Resonances, $C=0$}

In the case of multiple resonances $N_{\mathrm{C}}, N_{\mathrm{D}} \geq 1$ and neglecting the interwinding capacitance $C$, the general formulas given in (1) and (2) can be written using the following expressions:

$$
\begin{aligned}
Z_{\mathrm{CM}} & =\sum_{i=0}^{N_{\mathrm{C}}} Z_{\mathrm{C} i} \\
& =R_{0}+\sum_{i=1}^{N_{\mathrm{C}}} \frac{\mathrm{j} \omega R_{\mathrm{C} i} L_{\mathrm{C} i}}{R_{\mathrm{C} i}-2 \omega^{2} R_{\mathrm{C} i} L_{\mathrm{C} i} C_{\mathrm{C} i}+2 \mathrm{j} \omega L_{\mathrm{C} i}} \\
Z_{\mathrm{DM}} & =\sum_{i=0}^{N_{\mathrm{D}}} Z_{\mathrm{D} i} \\
& =4 R_{0}+\sum_{i=1}^{N_{\mathrm{D}}} \frac{4 \mathrm{j} \omega R_{\mathrm{D} i} L_{\mathrm{D} i}}{R_{\mathrm{D} i}-2 \omega^{2} R_{\mathrm{D} i} L_{\mathrm{D} i} C_{\mathrm{D} i}+2 \mathrm{j} \omega L_{\mathrm{D} i}} .
\end{aligned}
$$

Typical behavior of these two impedances at lower frequencies is inductive; at higher frequencies, there may be several resonance effects taking place (solid line in Fig. 9). In order to extract the $R L C$ values of the equivalent circuit, we introduce the following four hypotheses:

1) at frequencies close to dc $\left(f_{0}\right)$, the impedance of the choke is resistive and defined by $Z_{0}$;

2) at lower frequencies $f_{1}$, the behavior of the impedance is ruled by the inductive behavior of $Z_{1}$;

3) a resonance at $f_{\mathrm{R} i}$ is caused by the parallel resonance circuit $Z_{i}$; the influence of other resonant stages $Z_{j}, j \neq i$ can be neglected;
4) an antiresonance at $f_{\mathrm{A} i}$ is caused by the resonant circuits $Z_{i}$ and $Z_{i+1}$ in series; the influence of other resonant stages $Z_{j}, j \neq i, i+1$ can be neglected.

These hypotheses when fulfilled allow for a straightforward, equation-based parameter extraction as it will be shown in what follows. In case the hypotheses are not fulfilled, the model is still valid, but the parameter extraction needs to be performed using an optimization procedure (as outlined in Section III-C).

Using these hypotheses, we first derive the equations for the extraction of the parameters belonging to the CM part of the equivalent circuit. The DM parameters can be then derived in a similar way. From 1), we have

$$
R_{0} \approx \operatorname{Re}\left(Z_{\mathrm{CM}}\left(f_{\mathrm{C} 0}\right)\right) .
$$

From 2), we have

$$
\left|Z_{\mathrm{CM}}\left(f_{\mathrm{C} 1}\right)\right| \approx 2 \pi f_{\mathrm{C} 1} L_{\mathrm{C} 1} \rightarrow L_{\mathrm{C} 1} \approx \frac{\left|Z_{\mathrm{CM}}\left(f_{\mathrm{C} 1}\right)\right|}{2 \pi f_{\mathrm{C} 1}} .
$$

From 3), we have that the resonance at $f_{\mathrm{CR} i}$ is produced by the $i$ th resonant stage $Z_{\mathrm{C} i}$ and therefore

$$
f_{\mathrm{CR} i} \approx \frac{1}{2 \pi \sqrt{2 L_{\mathrm{C} i} C_{\mathrm{C} i}}} \rightarrow C_{\mathrm{C} i} \approx \frac{1}{8 \pi^{2} f_{\mathrm{CR} i}^{2} L_{\mathrm{C} i}} .
$$

At this frequency, the impedance is real, and since the parallel resistance $R_{\mathrm{C} i} / 2$ is responsible for the damping in that case, one has

$$
R_{\mathrm{C} i} \approx 2\left|Z_{\mathrm{CM}}\left(f_{\mathrm{CR} i}\right)\right| .
$$

Supposing that the antiresonance $f_{\mathrm{CA} i}$ in the $\mathrm{CM}$ impedance is produced by the series resonance between $Z_{\mathrm{C} i}$ and $Z_{\mathrm{C} i+1}$ [hypothesis 4)], we can write

$$
f_{\mathrm{CA} i} \approx \frac{1}{2 \pi \sqrt{2 \frac{L_{\mathrm{C} i} L_{\mathrm{C} i+1}}{L_{\mathrm{C} i}+L_{\mathrm{C} i+1}}\left(C_{\mathrm{C} i}+C_{\mathrm{C} i+1}\right)}} .
$$

Combining (25) with (23) for $i$ and $i+1$, one obtains

$$
L_{\mathrm{C} i+1}=L_{\mathrm{C} i} \frac{1-\frac{f_{\mathrm{CA} i}^{2}}{f_{\mathrm{CR} i+1}^{2}}}{\frac{f_{\mathrm{CA} i}^{2}}{f_{\mathrm{CR} i}^{2}}-1} \quad \text { and } \quad C_{\mathrm{C} i+1}=C_{\mathrm{C} i} \frac{1-\frac{f_{\mathrm{CR} i}^{2}}{f_{\mathrm{CA} i}^{2}}}{\frac{f_{\mathrm{CR} i+1}^{2}}{f_{\mathrm{CA} i}^{2}}-1} .
$$

Equations (21) - (23) for $i=1$, and (24) and (26) form a set of equations that can be used in an iterative procedure for extracting the parameters in the CM part of the equivalent circuit. For completeness, this set of equations together with the equations for the DM part of the circuit are summarized in Tables III and IV, for single- and three-phase chokes, respectively. Note that the value of $R_{0}$ can be extracted from either CM or DM measurements.

\section{Multiple Resonances, $C>0$}

The extraction of the $R L C$ parameters of the choke model including interwinding capacitance is best done using curve fitting and optimization techniques. In this section, we give details of a genetic algorithm [26] approach that we have adopted in fitting the measured CM, DM, and OC impedance curves.

Curve fitting is a process of approximating a closed-form function from a given dataset. To express data in closed-form 
TABLE III

ITERATIVE FORMULAS FOR PARAMETER EXTRACTION OF A SingLE-PHASE CHOKE

\begin{tabular}{|c|c|}
\hline \multicolumn{2}{|c|}{ Single Phase, Multiple Resonances, $C=0$} \\
\hline $\mathrm{CM}$ & $\mathrm{DM}$ \\
\hline$R_{0} \approx \operatorname{Re}\left(Z_{\mathrm{CM}}\left(f_{\mathrm{C} 0}\right)\right)$ & or $R_{0} \approx \operatorname{Re}\left(Z_{\mathrm{DM}}\left(f_{\mathrm{D} 0}\right)\right) / 4$ \\
$L_{\mathrm{C} 1} \approx \frac{\left|Z_{\mathrm{CM}}\left(f_{\mathrm{C} 1}\right)\right|}{2 \pi f_{\mathrm{C} 1}}$ & $L_{\mathrm{D} 1} \approx \frac{\left|Z_{\mathrm{DM}}\left(f_{\mathrm{D} 1}\right)\right|}{8 \pi f_{\mathrm{D} 1}}$ \\
$C_{\mathrm{C} 1} \approx \frac{1}{8 \pi^{2} f_{\mathrm{CR} 1}^{2} L_{\mathrm{C} 1}}$ & $C_{\mathrm{D} 1} \approx \frac{1}{8 \pi^{2} f_{\mathrm{DR} 1}^{2} L_{\mathrm{D} 1}}$ \\
$L_{\mathrm{C} i+1}=L_{\mathrm{C} i} \frac{1-\frac{f_{\mathrm{CA} i}}{f_{\mathrm{CR} i+1}}}{\frac{f_{\mathrm{C} A}^{2}}{f_{\mathrm{CR} i}^{2}}}$ & $L_{\mathrm{D} i+1}=L_{\mathrm{D} i} \frac{1-\frac{f_{\mathrm{DA} i}^{2}}{f_{\mathrm{DR} i+1}^{2}}}{\frac{f_{\mathrm{DA} i}^{2}}{f_{\mathrm{DR} i}^{2}}}$ \\
$C_{\mathrm{C} i+1}=C_{\mathrm{C} i} \frac{1-\frac{f_{\mathrm{CR} i}^{2}}{f_{\mathrm{CA} i}^{2}}}{\frac{f_{\mathrm{CR} i+1}^{2}}{f_{\mathrm{CA} i}^{2}}-1}$ & $C_{\mathrm{D} i+1}=C_{\mathrm{D} i} \frac{1-\frac{f_{\mathrm{DR} i}^{2}}{f_{\mathrm{DA} i}^{2}}}{\frac{f_{\mathrm{DR} i+1}^{2}}{f_{\mathrm{DA} i}^{2}}-1}$ \\
$R_{\mathrm{C} i} \approx 2\left|Z_{\mathrm{CM}}\left(f_{\mathrm{CR} i}\right)\right|$ & $R_{\mathrm{D} i} \approx \frac{1}{2}\left|Z_{\mathrm{DM}}\left(f_{\mathrm{DR} i}\right)\right|$ \\
\hline
\end{tabular}

TABLE IV

ITERATIVE FORMULAS FOR PARAMETER EXTRACTION OF A THREE-PHASE CHOKE

\begin{tabular}{|c|c|}
\hline \multicolumn{2}{|c|}{ Three Phase, Multiple Resonances, $C=0$} \\
\hline $\mathrm{CM}$ & $\mathrm{DM}$ \\
\hline$R_{0} \approx \frac{3}{2} \operatorname{Re}\left(Z_{\mathrm{CM}}\left(f_{\mathrm{C} 0}\right)\right)$ & or $R_{0} \approx \operatorname{Re}\left(Z_{\mathrm{DM}}\left(f_{\mathrm{D} 0}\right)\right) / 3$ \\
$L_{\mathrm{C} 1} \approx \frac{\left|Z_{\mathrm{CM}}\left(f_{\mathrm{C} 1}\right)\right|}{2 \pi f_{\mathrm{C} 1}}$ & $L_{\mathrm{D} 1} \approx \frac{2\left|Z_{\mathrm{DM}}\left(f_{\mathrm{D} 1}\right)\right|}{9 \pi f_{\mathrm{D} 1}}$ \\
$C_{\mathrm{C} 1} \approx \frac{1}{12 \pi^{2} f_{\mathrm{CR} 1}^{2} L_{\mathrm{C} 1}}$ & $C_{\mathrm{D} 1} \approx \frac{1}{6 \pi^{2} f_{\mathrm{DR} 1}^{2} L_{\mathrm{D} 1}}$ \\
$L_{\mathrm{C} i+1}=L_{\mathrm{C} i} \frac{1-\frac{f_{\mathrm{CA} i}^{2}}{f_{\mathrm{CR} i+1}^{2}}}{\frac{f_{\mathrm{CA} i}^{2}}{f_{\mathrm{CR} i}^{2}}}$ & $L_{\mathrm{D} i+1}=L_{\mathrm{D} i} \frac{1-\frac{f_{\mathrm{DA} i}^{2}}{f_{\mathrm{DR} i+1}^{2}}}{\frac{f_{\mathrm{DA} i}^{2}}{f_{\mathrm{DR} i}^{2}}}$ \\
$C_{\mathrm{C} i+1}=C_{\mathrm{C} i} \frac{1-\frac{f_{\mathrm{CR} i}^{2}}{f_{\mathrm{CA} i}^{2}}}{\frac{f_{\mathrm{CRR} i 1}^{2}}{f_{\mathrm{CA} i}^{2}}-1}$ & $C_{\mathrm{D} i+1}=C_{\mathrm{D} i} \frac{1-\frac{f_{\mathrm{DR} i}^{2}}{f_{\mathrm{DA} i}^{2}}}{\frac{f_{\mathrm{DR} i+1}^{2}}{f_{\mathrm{DA} i}^{2}}-1}$ \\
$R_{\mathrm{C} i} \approx 3\left|Z_{\mathrm{CM}}\left(f_{\mathrm{CR} i}\right)\right|$ & $R_{\mathrm{D} i} \approx \frac{2}{3}\left|Z_{\mathrm{DM}}\left(f_{\mathrm{DR} i}\right)\right|$ \\
\hline
\end{tabular}

equations is useful for analysis and interpretation of the observed data. In the particular case of the multiresonance choke modeling procedure, three measured impedance curves (CM, DM, and OC) are fitted using closed form (1)-(3), respectively, with unknown variables $C_{\mathrm{C} i}, L_{\mathrm{C} i}, R_{\mathrm{C} i}$ for the $\mathrm{CM}$ impedance curve and $C_{\mathrm{D} i}, L_{\mathrm{D} i}, R_{\mathrm{D} i}$ for the $\mathrm{DM}$ and $\mathrm{OC}$ impedance curves. The $\mathrm{CM}$ and DM curves can have several pronounced resonances. To be able to cover $n$ resonances together with a tail of the last resonance peak, at least $n+1$ resonance stages from Fig. 1 will need to be included in the final equivalent circuit. This corresponds to $6(n+1)+2$ unknowns in the closed form (1)-(3). For example, measured characteristics with $n=5$ resonances in both CM and DM behavior would lead to the search for an optimal solution with the simultaneous variation of 38 dependent variables. This is a difficult task even for the modern computers. That is why several additional genetic evolution mechanisms have been developed to accelerate the fitting process.
1) Separate CM and DM fitting: Analysis of the closed-form impedance (1)-(3) shows that:

a) all impedance curves share only one common variable $R_{0}$;

b) curves $Z_{\mathrm{DM}}$ and $Z_{\mathrm{OC}}$ share the same set of variables.

This allows separate fitting of the curve $Z_{\mathrm{CM}}$ from one side and mutual fitting of curves $Z_{\mathrm{DM}}$ and $Z_{\mathrm{OC}}$ from another, resulting in a double reduction of unknowns in one fitting process. $R_{0}$, fitted in one process (e.g., $Z_{\mathrm{CM}}$ ), can be used as a constant in another one.

2) Constraints on the search space for each unknown: Although theoretically an impedance curve can be fitted using whatever values for $L_{i}, C_{i}$, and $R_{i}$, it is preferable to use realistic values for these parameters (e.g., a valid range for the intrawinding capacitance lies between $1 \mathrm{pF}$ and $1 \mu \mathrm{F}$ ). Thus, limiting the validity range for every variable will result in a realistic equivalent circuit and at the same time will significantly decrease the search space for the GA.

3) Cyclic change of fitness functions: Fitness function is a particular type of objective function that prescribes the optimality of a solution in a GA. In addition to using common square and least absolute deviations, we introduced an adapted weighted square deviation function, where the most weight has been given to the regions around the resonance and antiresonance peaks. This allows a fast finding of the resonance frequencies in the equivalent circuit and afterward a gradual improvement of fitting results with the common fitness functions. Another significant improvement to the convergence of the GA can be achieved using a technique we named "cyclic change of fitness function." The motivation is to prevent the GA from degradation (finding a local minimum of the fitness function and distributing the "genetic material," corresponding to this local minimum, to the majority of "species" in the population). As soon as the GA shows signs of degradation (no improvement in the minimum of a fitness function during several evolution cycles), the algorithm automatically switches to another fitness function, forcing the search to leave the local solution by introducing new (equivalent) optimization target. In fact, we just cyclically switch between few predefined fitness functions until no progress will be detected for all the available fitness functions. In this case, we assume that the global minimum for the different fitness functions is found.

4) Parallelization of the genetic search process: GA can be easily parallelized in a way, where several populations evolve independently, exchanging some of their individuals after certain number of evolution cycles. The idea behind is to find all resonance peaks as fast as possible. Using this information, the fitting process can be significantly accelerated. Moreover, if the size of the population is big enough (several thousands of species), the evolution process inside one population (crossover, mutation, and selection) can also be effectively parallelized. 


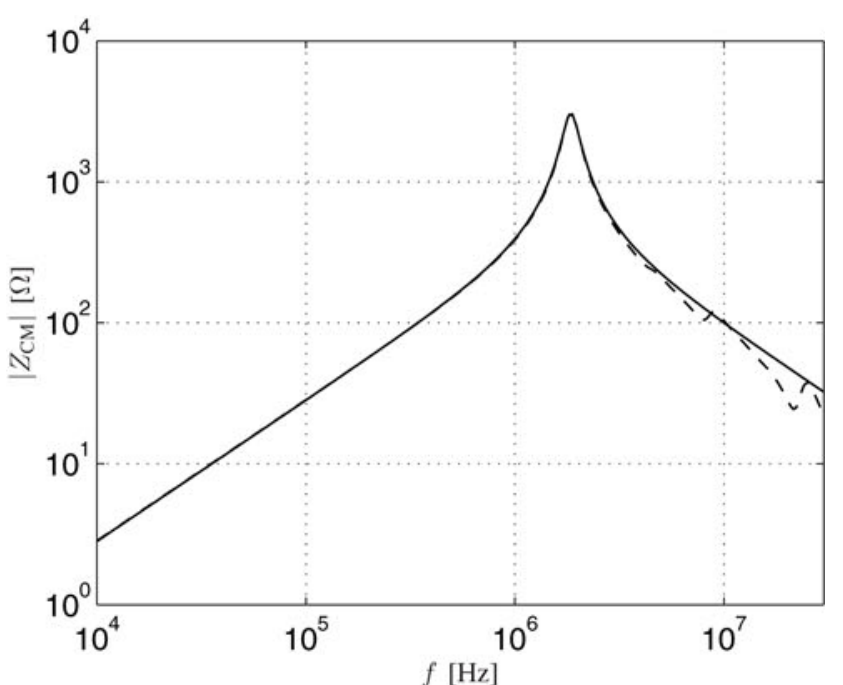

(a)

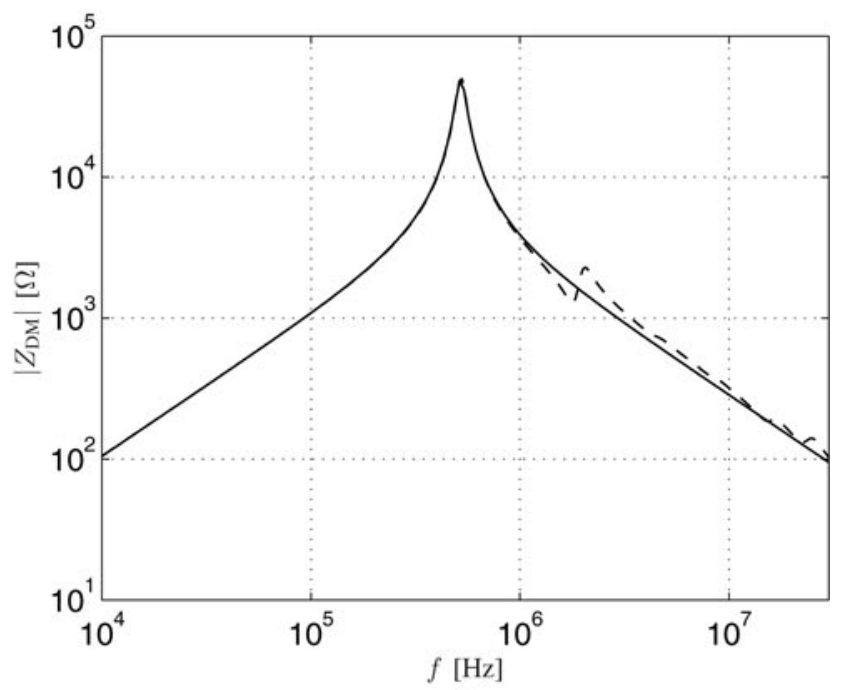

(b)

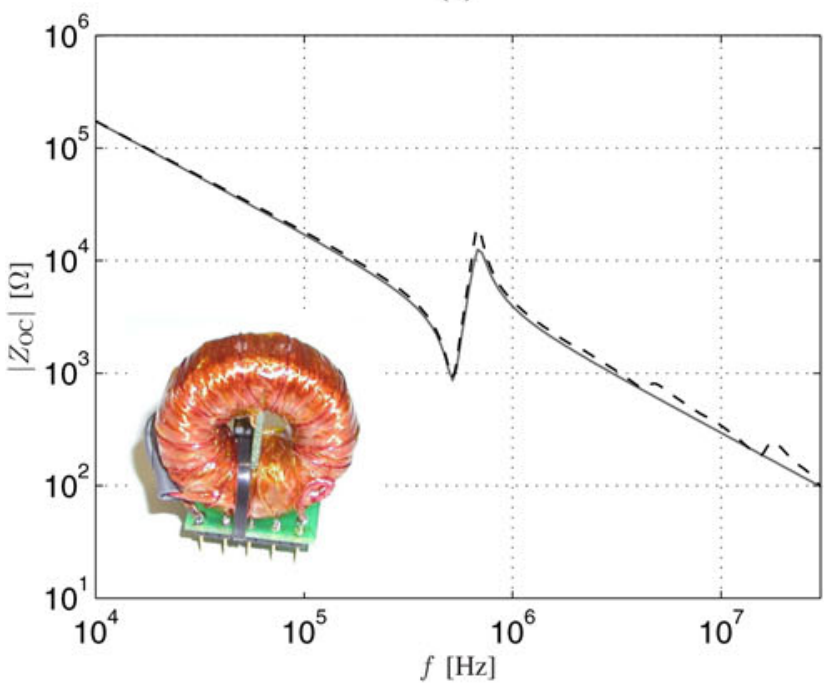

(c)

Fig. 10. Impedance of the single-phase coupled dc choke: simulations (solid lines) and measurements (dashed lines). (a) CM setup: $L_{\mathrm{C}}=44.9 \mathrm{mH}, C_{\mathrm{C}}=$ $82.2 \mathrm{pF}$, and $R_{\mathrm{C}}=6.2 \mathrm{k} \Omega$, (b) DM setup: $L_{\mathrm{D}}=416.4 \mu \mathrm{H}, C_{\mathrm{D}}=20 \mathrm{pF}$, and $R_{\mathrm{D}}=24.5 \mathrm{k} \Omega$, (c) OC setup: $C=45.9 \mathrm{pF}$.
TABLE V

PARAMETERS EXTRACTED FOR THE EPCOS Single-PHASE CHOKE

\begin{tabular}{|l|l|l|l|l|l|l|}
\hline$i$ & $R_{\mathrm{C} i}$ & $L_{\mathrm{C} i}$ & $C_{\mathrm{C} i}$ & $R_{\mathrm{D} i}$ & $L_{\mathrm{D} i}$ & $C_{\mathrm{D} i}$ \\
\hline 1 & $88.6 \mathrm{k} \Omega$ & $11.4 \mathrm{mH}$ & $48 \mathrm{pF}$ & $8.43 \mathrm{k} \Omega$ & $22.9 \mu \mathrm{H}$ & $76 \mathrm{pF}$ \\
\hline 2 & $2.72 \mathrm{k} \Omega$ & $1.3 \mu \mathrm{H}$ & $38 \mathrm{pF}$ & $1.92 \mathrm{k} \Omega$ & $2.1 \mu \mathrm{H}$ & $52 \mathrm{pF}$ \\
\hline 3 & $1.62 \mathrm{k} \Omega$ & $405 \mathrm{nH}$ & $26 \mathrm{pF}$ & $430 \Omega$ & $143 \mathrm{nH}$ & $64 \mathrm{pF}$ \\
\hline 4 & $740 \Omega$ & $63 \mathrm{nH}$ & $41 \mathrm{pF}$ & $340 \Omega$ & $62 \mathrm{nH}$ & $49 \mathrm{pF}$ \\
\hline 5 & $370 \Omega$ & $20 \mathrm{nH}$ & $64 \mathrm{pF}$ & $352 \Omega$ & $47 \mathrm{nH}$ & $21 \mathrm{pF}$ \\
\hline
\end{tabular}

\section{MEASUREMENTS AND CHARACTERIZATION}

Several different chokes have been measured and characterized using the theory outlined in the previous sections. The measurements have been performed using an impedance analyzer in the frequency range $[100 \mathrm{~Hz}, 100 \mathrm{MHz}]$ in $\mathrm{CM}, \mathrm{DM}$, and $\mathrm{OC}$ configurations. In this section, we validate our technique and show that it is equally applicable to characterizing single- and three-phase chokes over the whole measured frequency range.

\section{A. Single-Phase Coupled DC Choke}

In this section, we characterize a coupled dc choke using the procedure described in Section III-A. Using the measured values of the impedance, the equivalent parameters have been extracted and are listed in the captions of Fig. 10, where the values of the coupled dc choke input impedance for the three configurations are shown. The measured values are presented with dashed lines and the values obtained from simulation (using the extracted parameters) are shown with solid lines and agree well with the measurements.

\section{B. Single-Phase CM Choke}

We characterized an EPCOS CM choke with data sheet characteristics of $12 \mathrm{mH}$ (B82724J2302N021) with multiple resonances observed in the measured values of impedances. The equivalent parameters have been extracted using the procedure described in Section III-B and are listed in Table V. The parameter $R_{0}=62 \mathrm{~m} \Omega$ is extracted from the DM measurements. Fig. 11 shows good agreement of the simulated values of the input impedance with measurements in both configurations.

\section{Three-Phase CM Choke}

We have also performed measurements and characterization on an EPCOS $3 \times 3 \mathrm{mH}$ three-phase $\mathrm{CM}$ choke (B82747F4103N001), using the procedure explained in Section III-B. The extracted values of equivalent parameters are listed in Table VI. The parameter $R_{0}=9 \mathrm{~m} \Omega$ is extracted from the DM measurements. The model predicts well the measured values in the whole frequency range (see Fig. 12). 


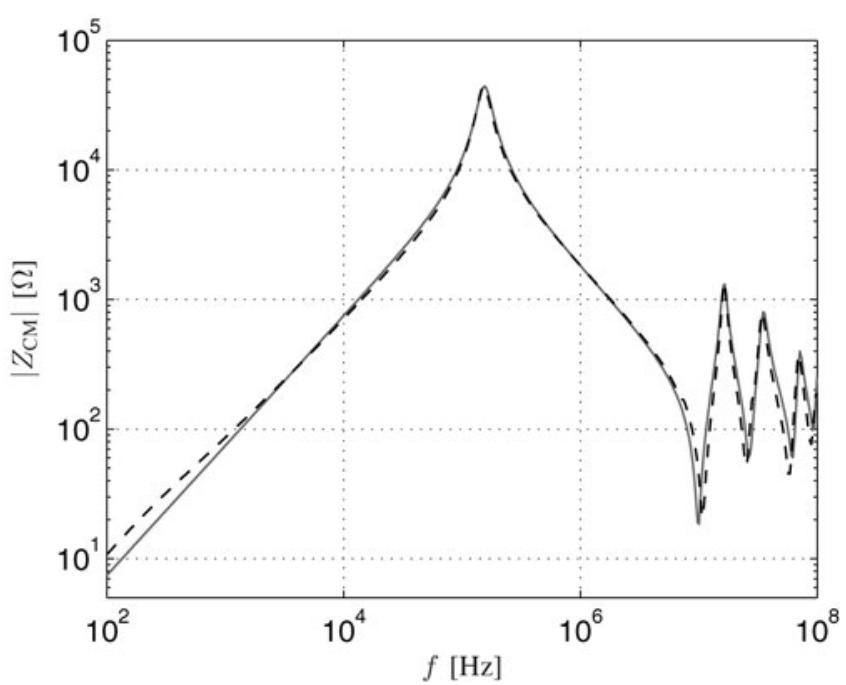

(a)

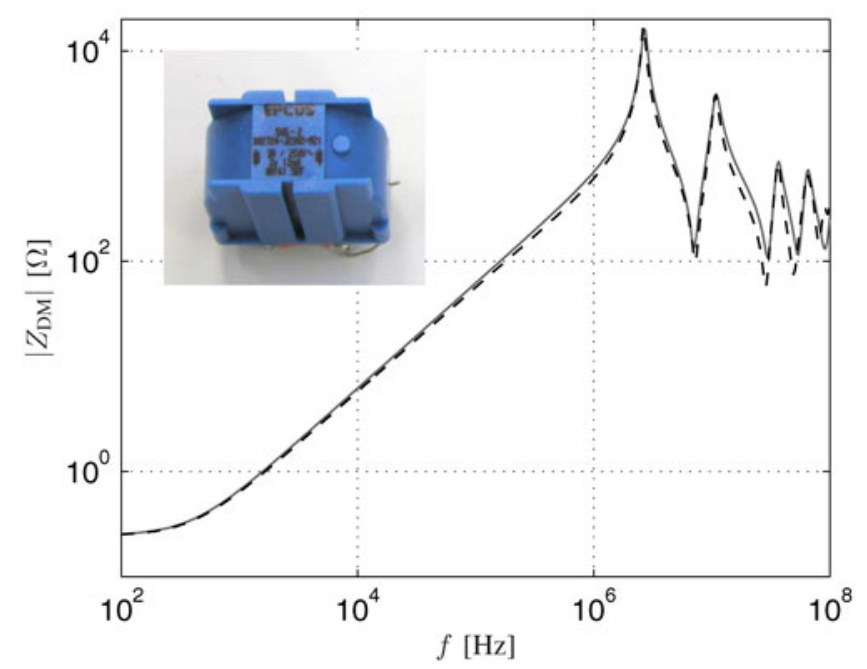

(b)

Fig. 11. Impedance of the single-phase choke: simulations (solid lines) and measurements (dashed lines). (a) CM setup. (b) DM setup.

TABLE VI

PARAMETERS EXTRACTED FOR THE EPCOS THREE-PHASE CHOKE

\begin{tabular}{|l|l|l|l|l|l|l|}
\hline$i$ & $R_{\mathrm{C} i}$ & $L_{\mathrm{C} i}$ & $C_{\mathrm{C} i}$ & $R_{\mathrm{D} i}$ & $L_{\mathrm{D} i}$ & $C_{\mathrm{D} i}$ \\
\hline 1 & $40 \mathrm{k} \Omega$ & $2.7 \mathrm{mH}$ & $16 \mathrm{pF}$ & $6.9 \mathrm{k} \Omega$ & $16.9 \mu \mathrm{H}$ & $36 \mathrm{pF}$ \\
\hline 2 & $738 \Omega$ & $88 \mathrm{nH}$ & $23 \mathrm{pF}$ & $907 \Omega$ & $779 \mathrm{nH}$ & $37 \mathrm{pF}$ \\
\hline 3 & - & - & - & $291 \Omega$ & $76 \mathrm{nH}$ & $57 \mathrm{pF}$ \\
\hline 4 & - & - & - & $188 \Omega$ & $45 \mathrm{nH}$ & $45 \mathrm{pF}$ \\
\hline
\end{tabular}

\section{Single-Phase Choke With Nanocrystalline Core}

The final example is a Magnetec $2 \times 32 \mathrm{mH} \mathrm{CM}$ choke with nanocrystalline core. The measured impedance characteristics exhibit multiple resonances and in addition do not satisfy the hypotheses that would allow the choke to be modeled analytically as shown in Section III-B. This is where the curve fitting with genetic algorithm from Section III-C become very useful. The genetic algorithm code has been implemented in Java utilizing standard evolution mechanisms [26] and the additional ones

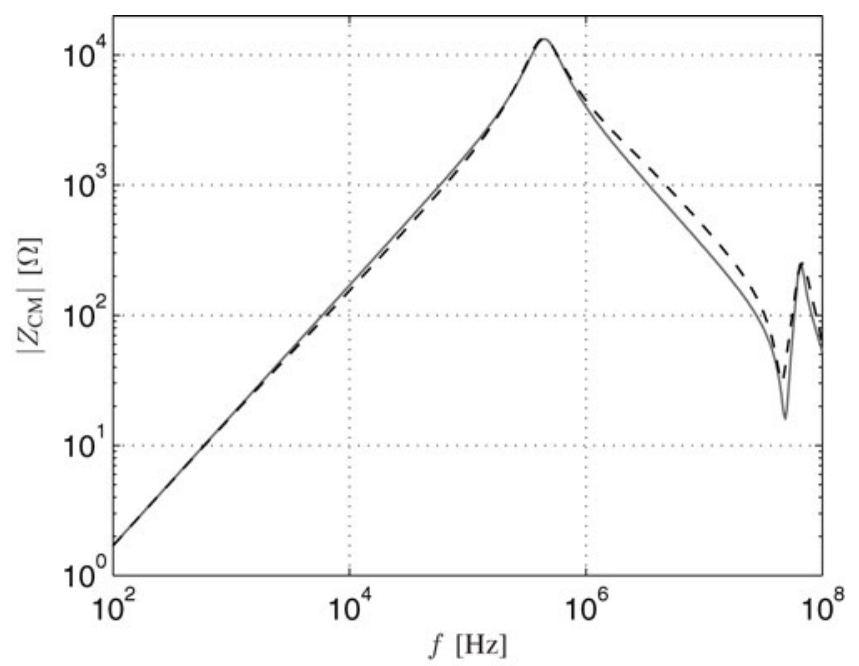

(a)

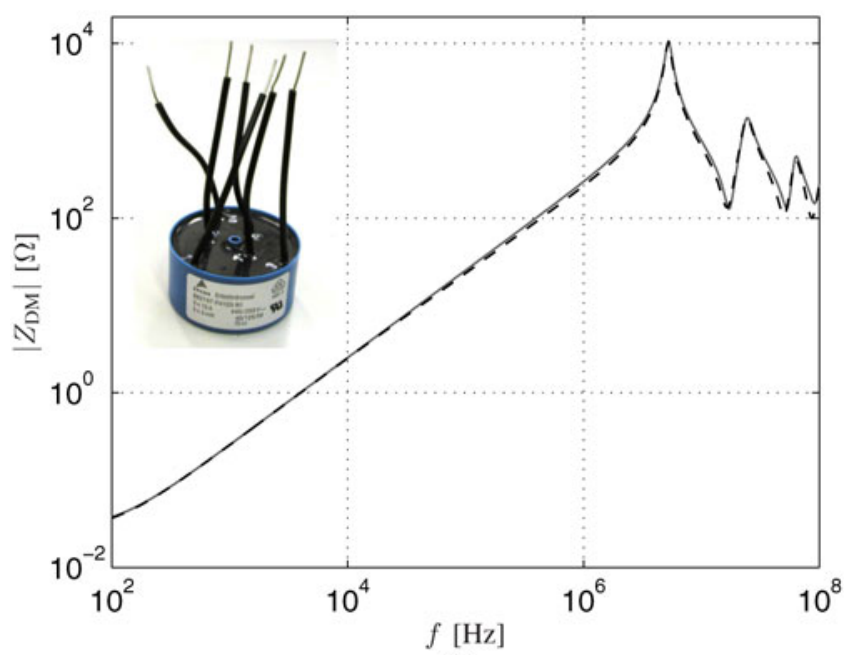

(b)

Fig. 12. Impedance of the three-phase choke: simulations (solid lines) and measurements (dashed lines). (a) CM setup. (b) DM setup.

TABLE VII

PARAMETERS EXTRACTED FOR THE MAGNETEC Single-Phase CHOKE

\begin{tabular}{|l|l|l|l|l|l|l|}
\hline$i$ & $R_{\mathrm{C} i}$ & $L_{\mathrm{C} i}$ & $C_{\mathrm{C} i}$ & $R_{\mathrm{D} i}$ & $L_{\mathrm{D} i}$ & $C_{\mathrm{D} i}$ \\
\hline 1 & $1.24 \mathrm{k} \Omega$ & $208 \mathrm{nH}$ & $4.4 \mathrm{pF}$ & $2.92 \mathrm{k} \Omega$ & $1.73 \mu \mathrm{H}$ & $10.8 \mathrm{pF}$ \\
\hline 2 & $5 \mathrm{k} \Omega$ & $10 \mathrm{mH}$ & $30.7 \mathrm{pF}$ & $3.2 \mathrm{k} \Omega$ & $207 \mathrm{nH}$ & $0.08 \mathrm{pF}$ \\
\hline 3 & $6.6 \mathrm{k} \Omega$ & $1 \mathrm{mH}$ & $19.3 \mathrm{pF}$ & - & - & - \\
\hline
\end{tabular}

described in Section III-C. The parameter extraction with satisfactory results has been achieved after approximately 15 min of simulation time on a modern two quad-core Intel Xeon workstation (seven cores have been used).

The extracted values of equivalent parameters are listed in Table VII. The parameters $R_{0}=5 \mathrm{~m} \Omega$ and $C=2.81 \mathrm{pF}$ are extracted from combined fitting of DM and OC measured impedance curves. The model predicts well the measured values in the whole frequency range (see Fig. 13). 


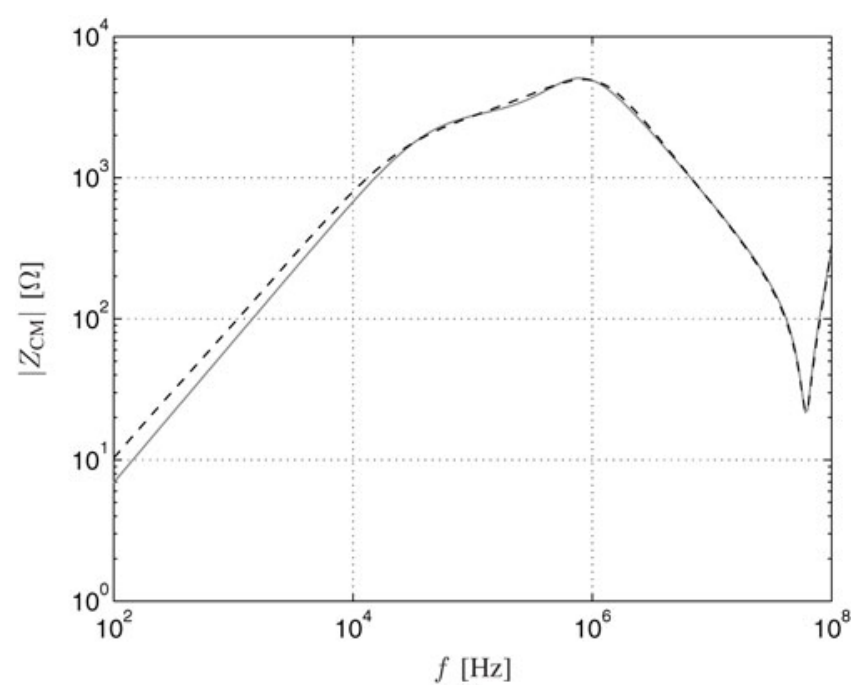

(a)

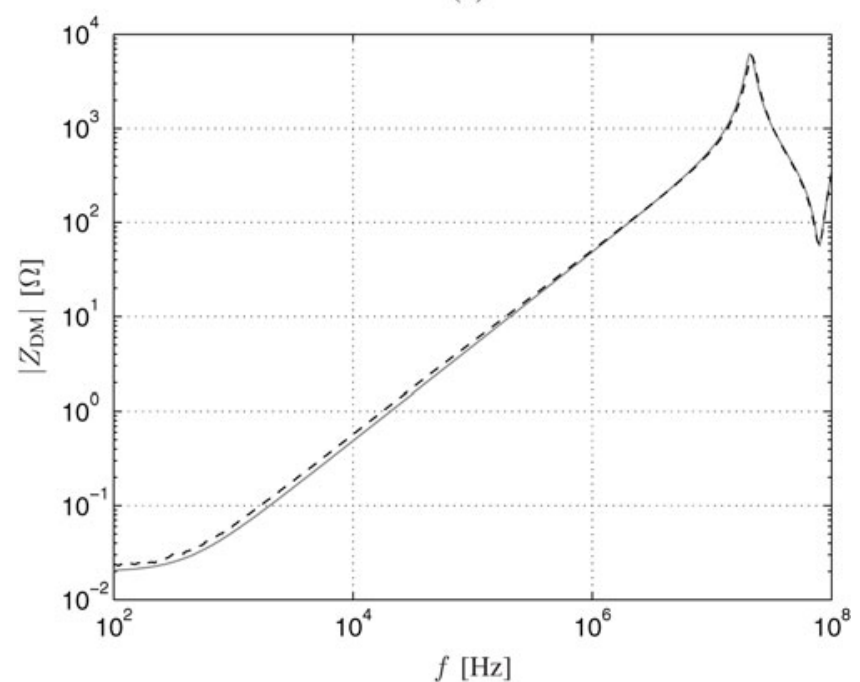

(b)

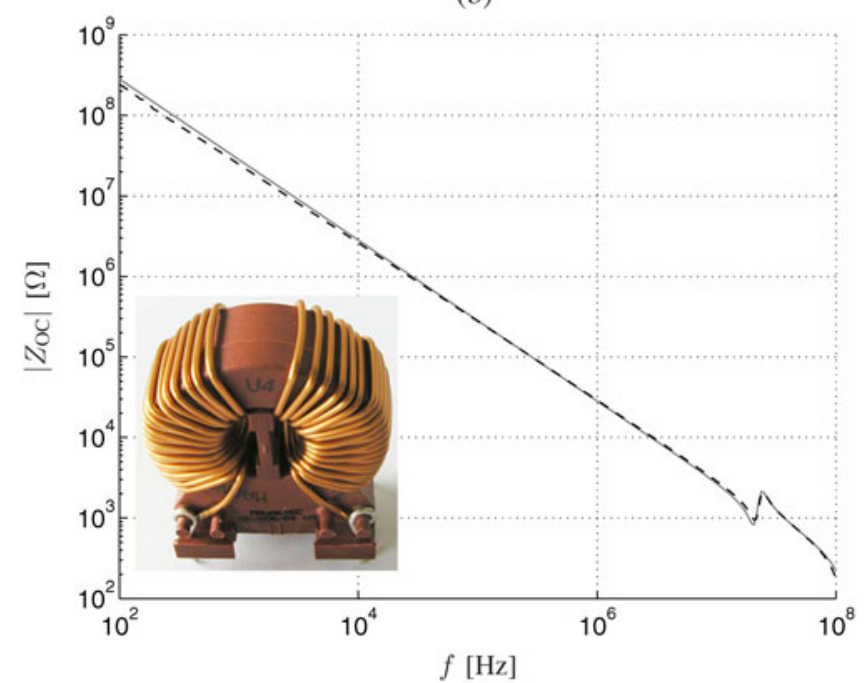

(c)

Fig. 13. Impedance of the Magnetec single-phase choke: simulations (solid lines) and measurements (dashed lines). (a) CM setup. (b) DM setup. (c) OC setup.

\section{CONCLUSION}

In this paper, a novel generalized behavioral model and parameter extraction procedure for single- and three-phase chokes have been presented. The modeling technique is based on the principle of fitting of characteristic curves (impedance curves) obtained from measurements at different connection schemes (CM, DM, and OC). Depending on the level of the model complexity, the model parameters can be computed either from a straightforward equation-based or an optimization-based parameter extraction procedure. As a result of the fitting procedure, an equivalent circuit fully representing the frequency behavior of the choke is created. Using this technique, several types of industrial chokes can be modeled such as single-phase inductors, coupled dc chokes, and single- and three-phase CM chokes. Optimization-based parameter extraction procedure (e.g., using genetic algorithm) also allows modeling of chokes with nonlinear core characteristics.

Several examples of application of the developed technique to the modeling of different types of industrial power electronics chokes are presented. To demonstrate the robustness of the method, the modeled frequency range has been extended to $(100 \mathrm{~Hz}-100 \mathrm{MHz})$ largely covering the EMI regulated frequency band. A very good agreement between measured and modeled curves has been achieved.

\section{REFERENCES}

[1] M. L. Heldwein and J. W. Kolar, "Winding capacitance cancellation for three-phase EMC input filters," IEEE Trans. Power Electron., vol. 23, no. 4, pp. 2062-2074, Jul. 2008.

[2] S. Wang, Y. Y. Maillet, F. Wang, D. Boroyevich, and R. Burgos, "Investigation of hybrid EMI filters for common-mode EMI suppression in a motor drive system," IEEE Trans. Power Electron., vol. 25, no. 4, pp. 1034-1045, Apr. 2010.

[3] M. Hartmann, H. Ertl, and J. W. Kolar, "EMI filter design for a $1 \mathrm{MHz}$, $10 \mathrm{~kW}$ three-phase/level PWM rectifier," IEEE Trans. Power Electron., vol. 26, no. 4, pp. 1192-1204, Apr. 2011.

[4] G. Zhu, B. A. McDonald, and K. Wang, "Modeling and analysis of coupled inductors in power converters," IEEE Trans. Power Electron., vol. 26, no. 5, pp. 1355-1363, May 2011.

[5] N. Zhu, J. Kang, B. Wu, and Y. Xiao, "An integrated ac choke design for common-mode current suppression in neutral-connected power converter systems," IEEE Trans. Power Electron., vol. 27, no. 3, pp. 1228-1236, Mar. 2012.

[6] D. Liu and J. Jiang, "High frequency model of common mode inductor for EMI analysis based on measurements," in Proc. IEEE Int. Symp. Electromagn. Compat., Minneapolis, MN, May 21-24, 2002, pp. 462465.

[7] G. P. Muyshondt and W. M. Portnoy, "Development of high frequency spice models for ferrite core inductors and transformers," in Proc. Ind. Appl. Soc. Annu. Meet. Conf. Rec., San Diego, CA, Oct. 1-5, 1989, pp. 1328-1333.

[8] M. K. Kazimierczuk, G. Sancineto, G. Grandi, U. Reggiani, and A. Massarini, "High-frequency small-signal model of ferrite core inductors," IEEE Trans. Magn., vol. 35, no. 5, pp. 4185-4191, Sep. 1999.

[9] M. J. Nave, "On modeling the common mode inductor," in Proc. IEEE Int. Symp. Electromagn. Compat., Aug. 12-16, 1991, pp. 452-457.

[10] A. Massarini, M. K. Kazimierczuk, and G. Grandi, "Lumped parameter models for single- and multiple-layer inductors," in Proc. 27th Power Electron. Spec. Conf., vol. 1, Baveno, Italy, Jun. 23-27, 1996, pp. 295301.

[11] P. F. Okyere and E. Habiger, "A novel physically-based PSPICEcompatible-model for common-mode chokes," in Proc. Int. Symp. Electromagn. Compat., 1999, pp. 33-36.

[12] S. Weber, M. Schinkel, E. Hoene, S. Guttowski, W. John, and H. Reichl, "Radio frequency characteristics of high power common-mode chokes," in Proc. IEEE Int. Zurich Symp. Electromagn. Compat., 2005, pp. 1-4. 
[13] S. Weber, M. Schinkel, S. Guttowski, W. John, and H. Reichl, "Calculating parasitic capacitance of three-phase common-mode chokes," in Proc. Power Convers. Intell. Motion, Nürnberg, Germany, 2005, pp. 1-6.

[14] C. R. Sullivan and A. Muetze, "Simulation model of common-mode chokes for high-power applications," in Proc. 42nd Ind. Appl. Conf., Sep. 23-27, 1999, pp. 1810-1815.

[15] A. Roc'h, H. Bergsma, D. Zhao, B. Ferreira, and F. Leferink, "A new behavioural model for performance evaluation of common mode chokes," in Proc. 10th Int. Zurich Symp. Electromagn. Compat., Munich, Germany, Sep. 24-28, 2007, pp. 501-504.

[16] A. Roc'h, H. Bergsma, D. Zhao, B. Ferreira, and F. Leferink, "Performance optimization aspects of common mode chokes," in Proc. AsiaPacific Symp. Electromagn. Compat. 19th Int. Zurich Symp. Electromagn. Compat., Singapore, May 19-22, 2008, pp. 439-442.

[17] H. Chen, Z. Quian, S. Yang, and C. Wolf, "Finite-element modeling of saturation effect excited by differential-mode current in a common-mode choke," IEEE Trans. Power Electron., vol. 24, no. 3, pp. 873-877, Mar. 2009.

[18] M. Kovacic, Z. Hanic, S. Stipetic, S. Krishnamurthy, and D. Zarko, "Analytical wideband model of a common-mode choke," IEEE Trans. Power Electron., vol. 27, no. 7, pp. 3173-3185, Jul. 2012.

[19] Z. Li, D. Pommerenke, and Y. Shimoshio, "Common-mode and differential-mode analysis of common mode chokes," in Proc. Int. Symp. Electromagn. Compat., Aug. 18-22, 2003, pp. 384-387.

[20] C. Sullivan and A. Muetze, "Simulation model of common-mode chokes for high-power applications," IEEE Trans. Ind. Appl., vol. 46, no. 2, pp. 884-891, Mar./Apr. 2010.

[21] A. M. Sánchez, A. Pérez, J. R. Regué, M. Ribó, P. Rodríguez-Cepeda, and F. J. Pajares, "A modal model of common-mode chokes for conducted interference prediction," IEEE Trans. Electromagn. Compat., vol. 52, no. 3, pp. 749-752, Aug. 2010.

[22] J.-L. Kotny, X. Margueron, and N. Idir, "High-frequency model of the coupled inductors used in EMI filters," IEEE Trans. Power Electron., vol. 27 , no. 6, pp. 2805-2812, Jun. 2012.

[23] I. Stevanović and S. Skibin, "Behavioral circuit modeling of single- and three-phase chokes for EMI simulations," in Proc. Int. Power Electron. Conf., Sapporo, Japan, Jun. 21-24, 2010, pp. 2867-2871.

[24] I. Stevanović and S. Skibin, "Behavioral circuit modeling of single- and three-phase chokes with multi-resonances," in Proc. IEEE 8th Int. Conf. Power Electron., Jeju, Korea, Jun. 1-3, 2011, pp. 435-439.

[25] S. Skibin and I. Stevanović, "Behavioral circuit modeling of chokes with multi-resonances using genetic algorithm," in Proc. IEEE Int. Symp. Electromagn. Compat., Long Beach, CA, Aug. 14-19, 2011, pp. 454-458.

[26] J. H. Holland, Adaptation in Natural and Artificial Systems. Ann Arbor, MI: Univ. of Michigan Press, 1975.

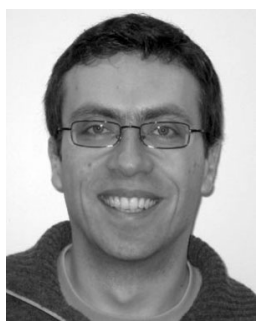

Ivica Stevanović (SM'12) received the Dipl.Ing. degree in electrical engineering from the University of Belgrade, Belgrade, Serbia, in 2000, and the Ph.D. degree in electrical engineering from the Ecole Polytechnique Fédérale de Lausanne (EPFL), Lausanne, Switzerland, in 2005.

In 2000, he was a Summer Undergraduate Research Fellow (SURF) with the Laser Interferometer Gravitational Wave Observatory, California Institute of Technology (Caltech), Pasadena. From 2000 to 2006, he was with the Laboratory of Electromagnetics and Acoustics (LEMA), EPFL, where he held the positions of Research and Teaching Assistant (from 2000 to 2005) and Postdoctoral Research Fellow (from 2005 to 2006). He was involved in several research projects for the European Space Agency, Swiss Federal Office of Communications, and the European Networks of Excellence on Metamaterials (Metamorphose) and Antennas (ACE). From 2006 to 2008, he was a Senior R\&D Engineer with Freescale Semiconductor (formerly Motorola), Geneva, Switzerland. Since 2008, he has been with ABB Corporate Research, Baden-Dättwil, Switzerland, where he currently holds the position of Principal Scientist. He is also an External Research Associate with the LEMA-EPFL. His research interests include numerical methods applied to electromagnetic problems and to statistical and compact modeling of integrated circuits.

Dr. Stevanovic was the recipient of an National Science Foundation-Research Experiences for Undergraduates-SURF Research Fellowship Award presented by Caltech in 2000 .

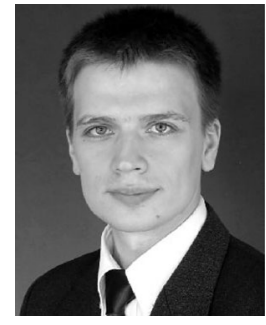

Stanislav Skibin (M'11) received the Diploma degree from the North Caucasus State University of Technology, Stavropol, Russia, in 1995, and the Ph.D. degree from the Hamburg University of Technology (TUHH), Hamburg, Germany, in 2005, both in electrical engineering.

From 2000 to 2006, he was with the Institute of Electromagnetic Theory, TUHH, where he held the positions of Research and Teaching Assistant. In March 2006, he joined ABB Corporate Research, where he currently holds the position of Principal Scientist. His research activity includes modeling and simulation of electromagnetic compatibility/electromagnetic interference in power electronics components and systems.

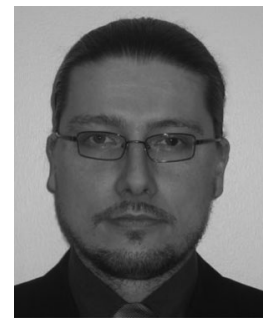

Mika Masti received the M.Sc. and D.Sc. degrees in electrical engineering from the Tampere University of Technology, Tampere, Finland, in 2000 and 2006, respectively.

His M.Sc. and D.Sc. theses were focused on applied superconductivity, which was his main research interest. For the last six years, he has been with ABB Oy Drives, Helsinki, Finland, developing mainly electromagnetic interference (EMI) simulation techniques, models, and processes. His current research interests include EMI simulation and modeling together with EMI behavior optimization of power converter systems.

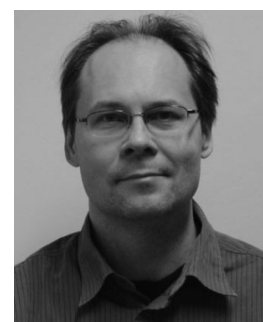

Matti Laitinen received the M.Sc. degree in electrical engineering from the Tampere University of Technology, Tampere, Finland, in 1994.

Since then, he has been with ABB Oy Drives, Helsinki, Finland, where he currently holds a position of Senior Principal Engineer and is involved in various engineering and management positions in research and development of low-voltage frequency converters. 